DOI: 10.36868/ejmse.2020.05.03.161

\title{
THE PREPARATION OF NBR/ENR COMPOSITE FOR OIL SEAL APPLICATIONS
}

\author{
Hesty Eka MAYASARI ${ }^{1}$, Muhammad SHOLEH ${ }^{2, *}$, Norma Arisanti KINASIH ${ }^{3}$, Muh Wahyu \\ SYA’BANI $^{4}$, Bidhari PIDHATIKA ${ }^{2}$ \\ ${ }^{1}$ Center for Industrial Research and Standardization of Surabaya, Jl. Jagir Wonokromo 360, Surabaya, Indonesia \\ ${ }^{2}$ Center for Leather, Rubber, and Plastics, Jl. Sokonandi No.9, Yogyakarta, Indonesia \\ ${ }^{3}$ Research Center for Rubber Technology, Jl. Salak No. 1, Bogor, Indonesia \\ ${ }^{4}$ Department of Rubber and Plastic Processing Technology, Politeknik ATK, Jl. Prof. Dr. Wirjono Projodikoro, \\ Yogyakarta, Indonesia
}

\begin{abstract}
The objective of this study was to determine the mechanical, swelling, and thermal properties of nitrile butadiene rubber (NBR)/epoxidized natural rubber (ENR) composite for oil seal applications. The blend was prepared with different ENR content and different plasticizer type (paraffinic oil and dioctyl phthalate). The composites were prepared by open milling process where the different amount of ENR was added ranging from 0 to 20 phr. Test results showed that dioctyl phthalate provides better compression set, swelling, and aging properties than paraffinic oil. Physical properties were not affected by ENR content up to $20 \mathrm{phr}$. The most promising sample from the study contains NBR $80 \mathrm{phr}$, ENR $20 \mathrm{phr}$, and dioctyl phthalate as a plasticizer.
\end{abstract}

Keywords: mechanical properties, oil seal, plasticizer, rubber blend, swelling.

\section{Introduction}

The rapid growth in the automotive sector has increased the demand in automotive spare parts, including those made of rubber materials. One of the important spare parts components in the automotive sector is an oil seal in cars. Seals in general, are used to prevent the leakage of fluids from a container. Rubber with elastic and flexible properties is a more appropriate material for sealing and preventing fluid leakage [1]. Rubber seals are normally chosen based on chemical compatibility with the fluid, which is not degraded upon contact with the fluid. However, no seal materials are one hundred percent solid. The fluid can diffuse into the voids and create swelling under pressure condition. This diffusion process is enhanced at high temperature and pressure. When the internal pressure exceeds a critical level, the void can further expand, form a blister or rupture, and the lifetime of the seal ends. In general, blister and rupture of seals are easily formed when the rubber material possesses low crosslink density, low hardness, and high elongation at break (>200\%) [1]. If a rubber sample is subjected to several successive stretches followed by retractions, at a certain point the sample reaches a limit where the retracted length is longer than the original unstretched length. This phenomenon determines the permanent set of a sample. In practice, this phenomenon also occurs during compressive stresses. For seal applications, the permanent set should be as low as possible [1].

Nitrile butadiene rubber (NBR) is well known for oil resistance and impermeability, good application and has been widely used as seals and gaskets in the sealing of oil. The import rate of nitrile rubber is still high in Indonesia. Meanwhile, the abundant availability of natural rubber (NR) has triggered a plethora of research using the material, for numerous applications. 
However, virgin NR, possesses relatively poor oil resistance compared to NBR. Modifications to improve oil resistance of NR include the synthesis of epoxidized natural rubber (ENR). ENR is natural rubber with a certain content of epoxide groups along its polymer chains. In general, swelling resistance, gas impermeability, hysteresis, and glass transition temperature (Tg) increases with increasing epoxide content. However, the resilience decreases with increasing epoxide content. ENR-50 has unique properties such as good oil resistance, low gas permeability, high tensile strength, improved wet grip and rolling resistance [2].

Blending of ENR with other types of rubber to achieve favorable properties in various final products has been reported in the literature. Perera et al. [3] reported the blending of PVC and ENR. The authors described that PVC is expected to impart high tensile strength and good chemical resistance, while ENR acts as a permanent plasticizer for PVC that induces good tear strength and enhances resistance against hydrocarbon oils. Numerous reports have been published on NBR/ENR mixtures and their properties. In the published reports, ENR has been used as either the main component or compatibilizer [2][4][5].

Our study utilized NBR and ENR-50 as two main polymers in the preparation process of oil seal materials. Although the mixture of NBR/ENR is not something new, to the best of our knowledge, there have never been any systematic reports on the mentioned mixture that is dedicated to seal applications. Furthermore, the variation of plasticizer type (polar DOP and non-polar paraffinic oil) into the NBR/ENR mixture in the study gives additional novelty into this article.

\section{Materials and Methods}

\section{Materials}

Epoxidized natural rubber (ENR50) was obtained from Malaysian Rubber Board. Nitrile butadiene rubber (NBR) Krynac 4975 was purchased from Lanxess. The other additives materials are paraffin wax Antilux 654A (Rhein Chemie) and 2,2,4-trimethyl-1,2dihydroquinoline (TMQ) (Kemai) as antioxidants, N-(1,3-dimethylbutyl)-N'-phenyl-pphenylenediamine (6-PPD) (Starchem) as an antiozonant, zinc oxide (Indoxide) and stearic acid Aflux 42M (Rhein Chemie) as activators, carbon black HAF N330 and carbon black SRF N770 (OCI) as fillers, sulfur (Miwon) as a vulcanizing agent, 2,2'-dithiobis(benzothiazole) (MBTS) (Shandong Sianxian) and tetramethylthiuram disulphide (TMTD) (Starchem) as accelerators. The plasticizers, dioctyl phthalate (DOP) and paraffinic oil, as well as IRM 903 and commercial engine oil (ShellTM) for swelling and solubility testing, were purchased in local market in Indonesia.

\section{Compounding and vulcanization}

The oil seal compound was prepared with different ENR content and different plasticizer type. The composition of NBR/ENR blend was tabulated in Table 1. The compounding process was performed on a laboratory two-roll-mill equipment. The vulcanization process conditions were studied using a rheometer at $150^{\circ} \mathrm{C}$. Applying the vulcanization parameter values suggested from rheometry experiments, the resultant NBR/ENR compound was then compression-molded to a $90 \%$ cure using a hydraulic press to obtain vulcanized rubber and oil seal prototype.

\section{Characterization}

The main materials used as the polymeric matrix, i.e. NBR and ENR, were characterized using a Fourier transform infrared spectrometer (PerkinElmer Spectrum Version 10) and a Mooney viscometer (Monsanto). Scorch time and cure time values of the NBR/ENR blend compounds were assessed by a moving die rheometer (Gotech 3000A) according to ASTM D2084-01 using a test temperature of $150^{\circ} \mathrm{C}$. 
A Shore A hardness tester (Tecklock) was used for the hardness tests, with the test conditions by following ASTM D2240-05. The tensile strength and elongation at break of the dumbbellshaped test specimens were measured according to ASTM D412-06 using a universal testing machine (Tinius Olsen $\mathrm{H} 25 \mathrm{~K}$ ). The characterization was performed both before and after aging at $100^{\circ} \mathrm{C}$ for $72 \mathrm{~h}$.

The compression set test was done according to ASTM D395. The test specimen was a cylindrical shape of $25 \pm 0.1 \mathrm{~mm}$ diameter and $12 \pm 0.5 \mathrm{~mm}$ thickness. The test specimen was placed between the plates of the compression device with spacers on each side of it. The percentage of the compression employed was $25 \%$ of the original thickness. Then the assembled compression device was placed in the oven at $70^{\circ} \mathrm{C}$ for $72 \mathrm{~h}$. After the test, the specimen was removed and allowed to cool for $30 \mathrm{~min}$. After this rest time the final thickness was measured by a digital caliper [6].

The swelling test was carried out according to ASTM D3616. Specimen with a thickness $(2 \pm 0.2) \mathrm{mm}$ was immersed in IRM 903 and Shell ${ }^{\circledR}$ commercial engine oil at $100^{\circ} \mathrm{C}$ for $72 \mathrm{~h}$. The ratio between the weights of the samples after and before immersion was expressed as the swelling factor.

The thermogravimetry (TG) was performed to study the thermal properties of the prepared seal samples. The thermogravimetric analysis was done using Shimadzu DTG-60H. Around $10 \mathrm{mg} \mathrm{NR} / \mathrm{ENR}$ sample was heated with a heating rate of $10^{\circ} \mathrm{C} / \mathrm{min}$ using an alumina pan in the air atmosphere at $30-300^{\circ} \mathrm{C}$. A scanning electron microscope (SNE 4500M) was used to study the morphology of the seal's cross-section specimen after sputter-coated with a thin layer of gold to avoid poor resolution during the examination.

Table 1. NBR/ENR compound formulations

\begin{tabular}{|c|c|c|c|c|c|c|c|c|c|c|}
\hline \multirow[t]{2}{*}{ Ingredient } & \multicolumn{10}{|c|}{ Amount (phr*) } \\
\hline & $\begin{array}{l}\text { SD1 } \\
\text { (p.o) }\end{array}$ & $\begin{array}{l}\text { SD2 } \\
\text { (p.o) }\end{array}$ & $\begin{array}{l}\text { SD3 } \\
\text { (p.o) }\end{array}$ & $\begin{array}{l}\text { SD4 } \\
\text { (p.o) }\end{array}$ & $\begin{array}{l}\text { SD5 } \\
\text { (p.o) }\end{array}$ & $\begin{array}{c}\text { SD1 } \\
\text { (DOP) }\end{array}$ & $\begin{array}{c}\text { SD2 } \\
\text { (DOP) }\end{array}$ & $\begin{array}{c}\text { SD3 } \\
\text { (DOP) }\end{array}$ & $\begin{array}{c}\text { SD4 } \\
\text { (DOP) }\end{array}$ & $\begin{array}{c}\text { SD5 } \\
\text { (DOP) }\end{array}$ \\
\hline NBR & 100 & 95 & 90 & 85 & 80 & 100 & 95 & 90 & 85 & 80 \\
\hline ENR & 0 & 5 & 10 & 15 & 20 & 0 & 5 & 10 & 15 & 20 \\
\hline Zinc oxide & 5 & 5 & 5 & 5 & 5 & 5 & 5 & 5 & 5 & 5 \\
\hline Aflux $42 \mathrm{M}$ & 1 & 1 & 1 & 1 & 1 & 1 & 1 & 1 & 1 & 1 \\
\hline HAF Black (N 330) & 20 & 20 & 20 & 20 & 20 & 20 & 20 & 20 & 20 & 20 \\
\hline SRF Black (N 770) & 20 & 20 & 20 & 20 & 20 & 20 & 20 & 20 & 20 & 20 \\
\hline Paraffinic oil & 10 & 10 & 10 & 10 & 10 & - & - & - & - & - \\
\hline DOP & - & - & - & - & - & 10 & 10 & 10 & 10 & 10 \\
\hline Paraffin wax & 0.5 & 0.5 & 0.5 & 0.5 & 0.5 & 0.5 & 0.5 & 0.5 & 0.5 & 0.5 \\
\hline 6-PPD & 2 & 2 & 2 & 2 & 2 & 2 & 2 & 2 & 2 & 2 \\
\hline TMQ & 2 & 2 & 2 & 2 & 2 & 2 & 2 & 2 & 2 & 2 \\
\hline MBTS & 1.5 & 1.5 & 1.5 & 1.5 & 1.5 & 1.5 & 1.5 & 1.5 & 1.5 & 1.5 \\
\hline TMTD & 0.5 & 0.5 & 0.5 & 0.5 & 0.5 & 0.5 & 0.5 & 0.5 & 0.5 & 0.5 \\
\hline Sulfur & 1.5 & 1.5 & 1.5 & 1.5 & 1.5 & 1.5 & 1.5 & 1.5 & 1.5 & 1.5 \\
\hline
\end{tabular}

\section{Results and Discussion}

\section{Characterization of NBR and ENR}

Figure 1 shows FTIR spectra of both NBR and ENR. NBR curve shows nitrile stretching at $2238 \mathrm{~cm}^{-1}$ and C-H stretching of butadiene double bond at $969 \mathrm{~cm}^{-1}$ [7][8]. ENR curve shows a half ring and whole ring stretching of the epoxide ring at 873 and $1250 \mathrm{~cm}^{-1}$. The result is in agreement with the literature [9].

Mooney viscosity was measured using preheat time 1 minute with test time 4 minutes using a large rotor at $100^{\circ} \mathrm{C}$. The viscosity value obtained for NBR and ENR was 66 and 86, respectively. In particular, the value for ENR is significantly close to that reported in the literature [10], i.e. 80 . 


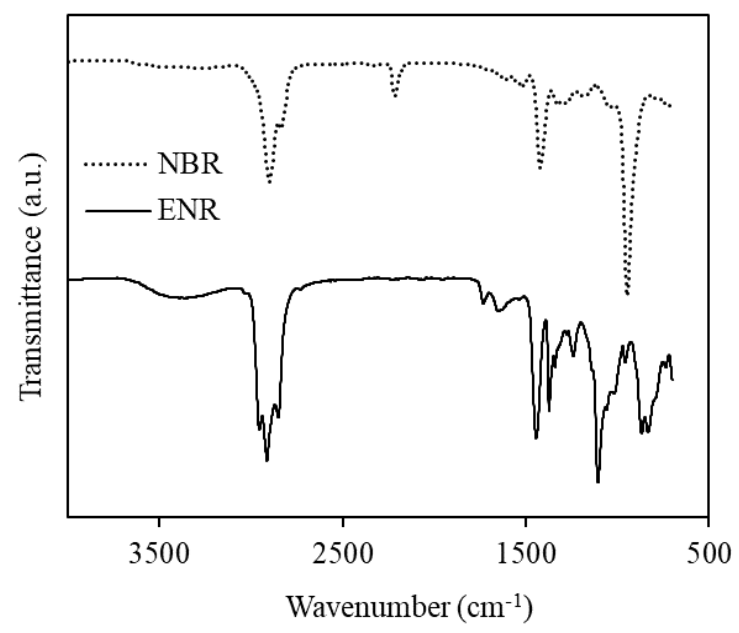

Fig. 1. The FTIR spectra of NBR and ENR

\section{Vulcanization characteristics}

The cure characteristics of the NBR/ENR compound as obtained from the MDR rheographs are summarized in Figure 2. The $t_{\mathrm{s} 2}$ is a measure of the scorch time while $t_{90}$ is the optimum cure time of the vulcanizate. Figure 2(a) shows that $t_{\mathrm{s} 2}$ is not affected by ENR levels up to $20 \mathrm{phr}$ while $t_{90}$ increases with increasing ENR levels. Scorch time of compound with DOP is higher than paraffinic oil, it means DOP provides better scorch safety compared to paraffinic oil.

The ML is considered as the elastic modulus of the uncured compound, while the MH as the modulus of the vulcanizate. The MH-ML is indirectly related to the crosslink density of the compounds [11]. Figure 2(b) shows that the minimum torque is not affected by ENR levels up to $20 \mathrm{phr}$. Vulcanisate with paraffinic oil as plasticizer gives a decrease in torque difference with increasing ENR levels.

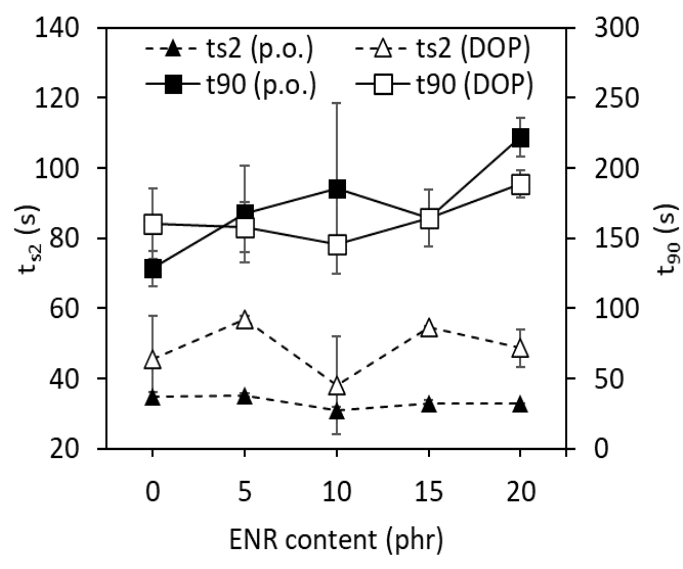

a)

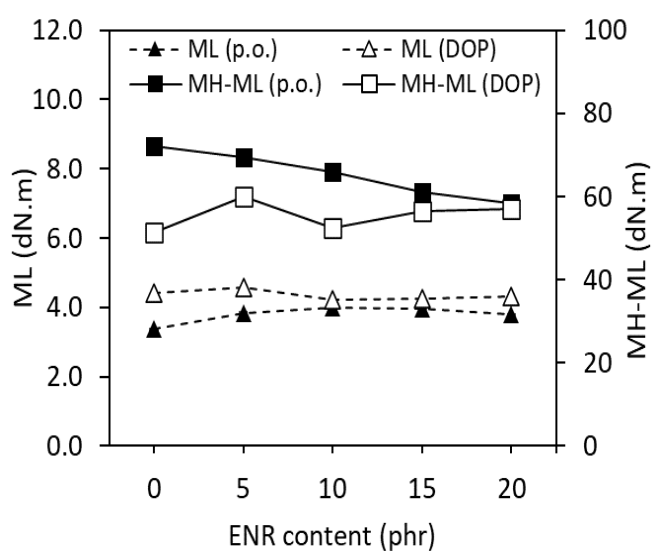

b)

Fig. 2. The effect of ENR loading on the vulcanization parameters determined from the curing curves: (a) scorch time $\left[\mathrm{t}_{\mathrm{s} 2}\right]$ and curing time $\left[\mathrm{t}_{90}\right]$, and (b) minimum torque $[\mathrm{ML}]$ and maximum torque $[\mathrm{MH}]$ 


\section{Hardness}

Figure 3 shows the hardness data before and after aging as a function of ENR content in the compound materials containing of either paraffinic oil or DOP as a plasticizer. It is seen in Figure 3 that hardness values are independent of ENR content in the experimental range of this study (0-20 phr). A similar result was found by George et al. for the CBS-DPG combination [4]. The influence of plasticizer was not pronounced before aging, however, it was pronounced after aging. Compared to the samples with DOP as a plasticizer, the samples with paraffinic oil show higher hardness values after aging, at all ENR contents. This observed phenomenon indicates that DOP is a more compatible plasticizer for the compound that slows down the aging rate of the materials. During aging at high temperature, further crosslinking between polymer chains might take place, resulting in higher hardness values and brittleness of the compound - something unwanted in sealing applications. It seems that DOP inhibits the further crosslinking process, thus slowing down the aging rate.

According to product specification of seals in contact with oil at high temperature [12], hardness value for commercial NBR seal is 65 Shore A. All prepared samples before aging meet this standard value.

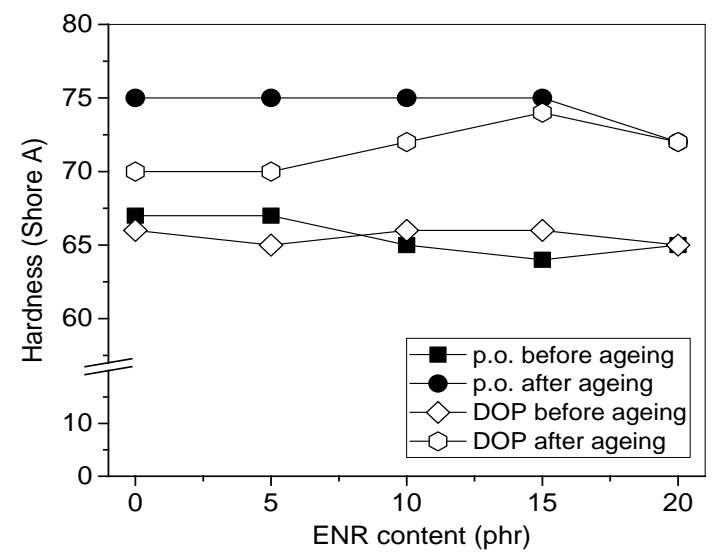

Fig. 3. The hardness value as a function of ENR content. The testing and aging procedure was performed according to ASTM D2240-05, at $100^{\circ} \mathrm{C}$ for $72 \mathrm{~h}$.

\section{Tensile Strength}

Figure 4 shows that TS values are independent of ENR content in the experimental range of this study (0-20 phr). The influence of plasticizer was not pronounced before aging, however, it was slightly pronounced after aging. Compared to the samples with DOP as a plasticizer, the samples with paraffinic oil show higher TS values after aging, at all ENR contents. This phenomenon is in agreement with the hardness data as described in the previous paragraph. The higher degree of crosslinking results in higher values of both hardness and TS, as observed in the paraffinic oil-containing compounds after aging at $100^{\circ} \mathrm{C}$ for $72 \mathrm{~h}$. Despite the slightly lower TS values after aging of DOP-containing compounds, the TS values of all prepared samples in this study $\left(14-18 \mathrm{~N} / \mathrm{mm}^{2}\right)$ are still high above the standard value for commercial NBR seal, which is $6 \mathrm{~N} / \mathrm{mm}^{2}$ [12].

\section{Elongation at break}

Figure 5 shows that EB values are independent of ENR content in the experimental range of this study. The influence of plasticizer was not pronounced both before and after aging. This observed phenomenon is interesting since natural rubber (NR) is, in general, known to have relatively high EB values compared to NBR. However, this study utilized ENR-50, i.e. 
natural rubber that has been $50 \%$ epoxidized. The epoxy (ring) content decreases the EB value of non-modified NR, leading to insignificant changes of EB values in NBR/ENR compound. Furthermore, it is seen that the EB value decreases after aging for all samples, from 350-500\% down to $200-250 \%$. This observed phenomenon is in agreement with two previous parameters, hardness and TS, as described in the previous paragraphs. Aging at high temperature increases the crosslinking density, increases hardness and TS, however, decreases EB value. This theory is true for all samples studied here.

Compared to commercial NBR seal for high-temperature applications [12], the EB values of all samples both before (350-500\%) and after (200-250\%) aging still meet the commercial standard $(250 \%)$.

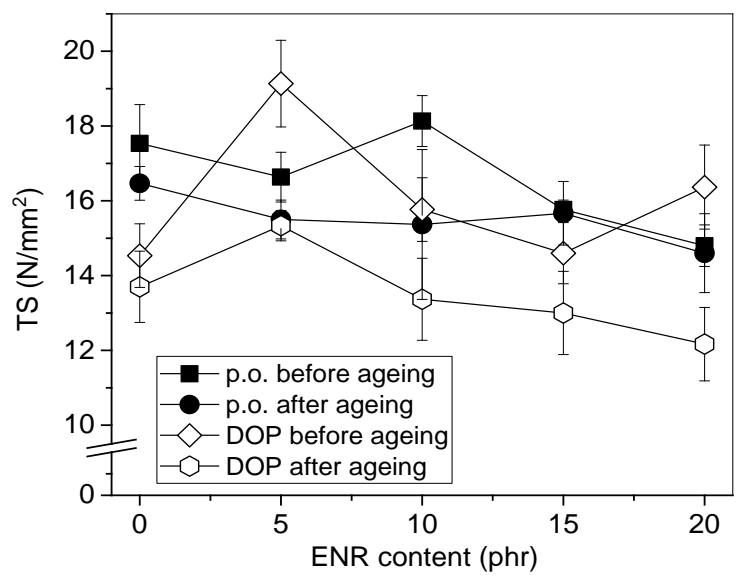

Fig. 4. The tensile strength (TS) value as a function of ENR content. The testing and aging procedure was performed according to ASTM D412-06a, at $100^{\circ} \mathrm{C}$ for $72 \mathrm{~h}$.

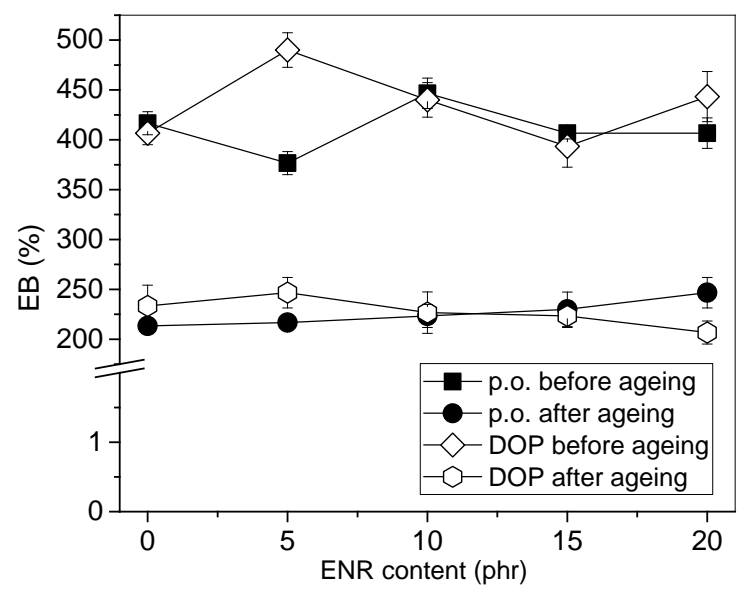

Fig. 5. The elongation at break (EB) value as a function of ENR content. The testing and aging procedure was performed according to ASTM D412-06a, at $100^{\circ} \mathrm{C}$ for $72 \mathrm{~h}$.

\section{Compression set (CS)}

It is seen that ENR content in the samples does not significantly influence the CS values (Figure 6). However, the plasticizer type does affect CS values significantly. DOP-containing compounds show significantly lower CS values (20-23\%) compared to paraffinic oil-containing 
compounds (22-30\%), at all ENR content. This is another indication that DOP is a more suitable plasticizer for NBR/ENR compound. According to specifications for NBR commercial seal with oil contact at high temperature, the CS value must be as low as $10-20 \%$ [12]. Thus, in this study only compounds with DOP plasticizer meet this standard.

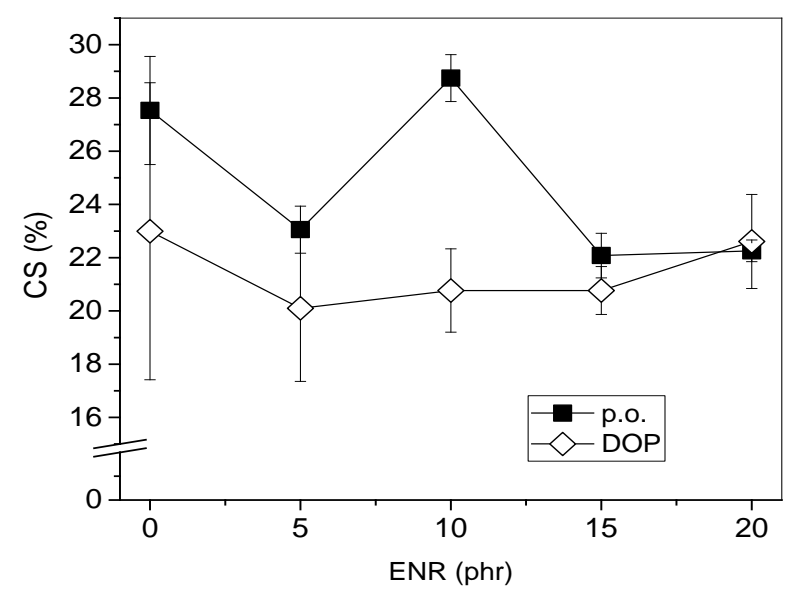

Fig. 6. The compression set (CS) value as a function of ENR-50 content. The testing procedure was performed according to ASTM D395-03, at $70^{\circ} \mathrm{C}$ for $72 \mathrm{~h}$.

\section{Swelling in oil medium}

Figure 7 shows the swelling factor of the seal samples as a function of incubation time in oil medium IRM 903 and commercial engine oil, at either room temperature or $100^{\circ} \mathrm{C}$. As comparators, virgin ENR and NBR, as well as two commercial oil seals, were included in the swelling factor experiments.

A moderate swelling can be accepted in seal applications, due to the increase of sealing ability when the seal swells. A moderate shrinkage is also accepted, however, with a risk of fluid leakage. Figure 7 shows the highest swelling factor as a function of time was observed on virgin ENR followed by virgin NBR samples in at room and high $\left(100^{\circ} \mathrm{C}\right)$ temperature. As shown in Figure 7(a) and (b), incubation at room temperature slightly increased the swelling factor of DOP-containing samples (up to 2\%), while paraffinic oil (p.o.)-containing ones decreased up to $2 \%$ of shrinkage. Meanwhile, Figure 7(c) and (d) show that the swelling factor of almost all samples (except virgin NBR, virgin ENR, and both commercial seals in IRM 903) decreased to negative values, which was shrinkage approximately $1-5 \%$ after immersion around 1250 minutes. The commercial samples and DOP-containing samples showed a lower degree of shrinkage compared to p.o.-containing samples. The value was close to standard [12] that tolerates a shrinkage down to $3 \%$ for NBR rubber seal at high temperature. Compared to p.o.containing samples, the DOP-containing samples showed better stability upon contact with an oil medium, both at room and high temperature.

\section{Thermal analysis}

Based on all experimental data showed previously in the above paragraphs, the sample that contains NBR $80 \mathrm{phr}$, ENR $20 \mathrm{phr}$, and DOP as plasticizer (denoted as SD5(DOP)) was considered as the most promising sample in seal applications. Thus, the sample was tested further with thermogravimetric analysis (TGA) in the air atmosphere to determine its stability against temperature increase. Two commercial seals were included in the analysis for comparison. The results of TGA is shown in Figure 8. 

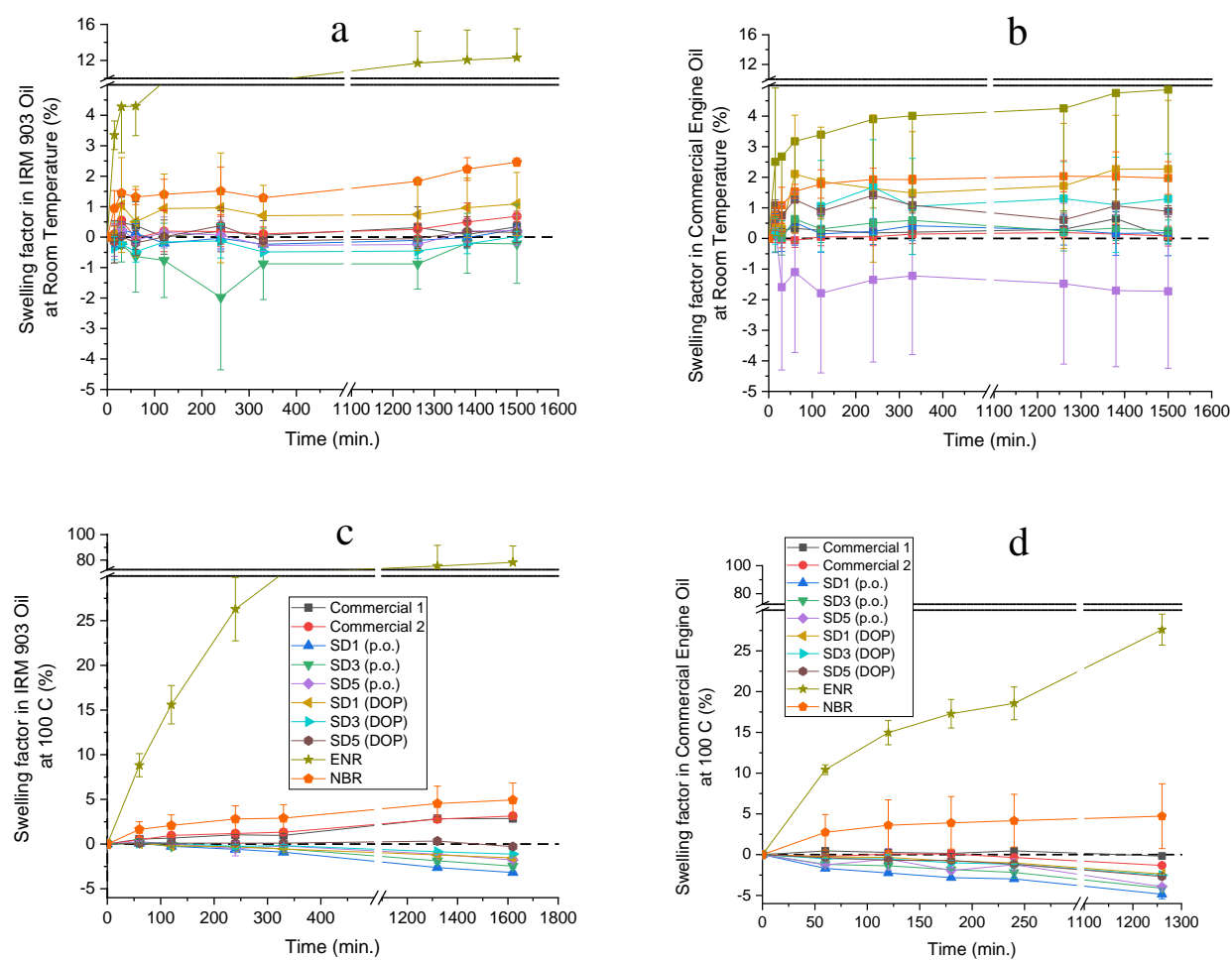

Fig. 7. Swelling factor of rubber seal prototype as a function of incubation time in oil medium IRM 903 and commercial engine oil, at room temperature $(\mathrm{a}$ and $\mathrm{b})$ and $100^{\circ} \mathrm{C}(\mathrm{c}$ and $\mathrm{d})$. The legends shown in $\mathrm{c}$ and $\mathrm{d}$ also apply for $\mathrm{a}$ and $\mathrm{b}$. The compound composition for SD1-SD5, both (p.o) and (DOP) can be seen in Table 1.

It is seen in Figure 8 that SD5(DOP) sample was stable (approximately 99\% remaining mass) up to $180^{\circ} \mathrm{C}$, i.e. comparable to both commercial seals. Above $180^{\circ} \mathrm{C}$, however, the remaining mass of SD5(DOP) sample drops down to $90 \%$ (at $300^{\circ} \mathrm{C}$ ), while the two commercial seals were more stable (96-97\% remaining mass at $\left.300^{\circ} \mathrm{C}\right)$. Since the sample was developed for oil seal in a car engine with maximum temperature $125^{\circ} \mathrm{C}$, the $\mathrm{SD} 5(\mathrm{DOP})$ sample was considered safe and applicable.

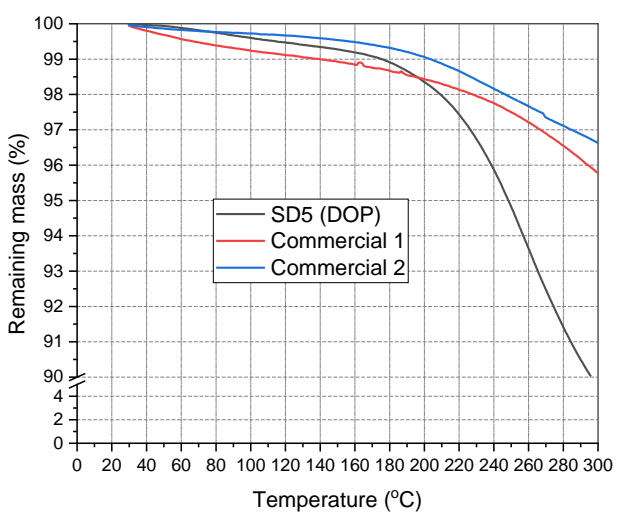

Fig. 8. The TGA graph: remaining mass as a function of temperature for commercial seals and SD5(DOP) sample. The TG experiment was performed under thermal rate increase $10^{\circ} \mathrm{C} / \mathrm{min}$. 


\section{Cross-section morphology}

Figure 9 shows the cross-section morphology of commercial seal 1, commercial seal 2, and SD5(DOP) sample. Some pores are seen on the SEM image of SD5(DOP) sample, while no pores were observed on both commercial seals.

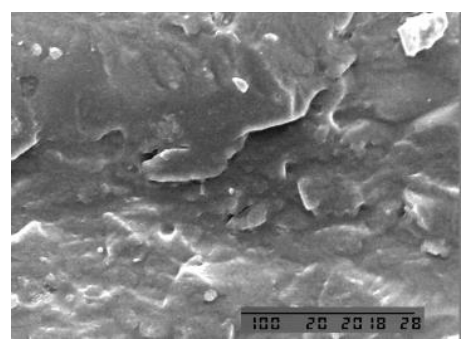

(a)

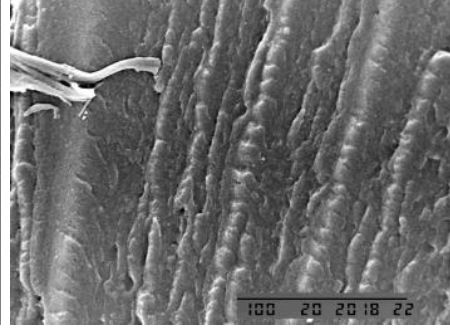

(b)

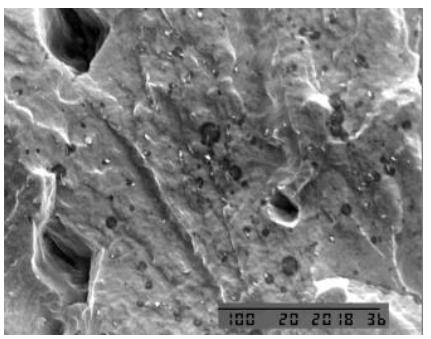

(c)

Fig. 9. The SEM micrographs of the cross-section of (a) commercial seal 1 (diesel engine), (b) commercial seal 2 (petrol engine), and (c) SD5(DOP) sample.

The pores lead to faster release of gases produced from the decomposition of the sample materials, leading to faster-observed mass drop, as observed in Figure 8.

\section{Conclusions}

The influence of ENR-50 substitution from 0 to $20 \mathrm{phr}$ in NBR for seal applications has been studied. It was found that the properties of the various compounds did not differ significantly, indicating that substitution of NBR with ENR up to 20 phr can be accepted in the targeted applications. Although further study must be done with higher ENR-50 content, the finding in the presented work is promising, in the context that dependency to synthetic rubber materials (NBR) might be suppressed. Apart from varying the rubber polymer composition, two different plasticizers, namely DOP and paraffinic oil, were used in the compound materials. Despite the fact that paraffinic oil is more environmentally friendly, DOP-containing compounds were found to have better properties compared to the paraffinic oil-containing compounds, for the targeted applications. The explanation of the observed phenomenon was the polarity issues, in which DOP is more polar compared to paraffinic oil, i.e. DOP's polarity is more similar to the rubber polymers' polarity. The most promising sample from the study contains NBR $80 \mathrm{phr}$, ENR $20 \mathrm{phr}$, and DOP as a plasticizer. The mentioned sample underwent $0 \%$ shrinkage in IRM 903 at $100^{\circ} \mathrm{C}, \leq 3 \%$ shrinkage in Shell ${ }^{\circledR}$ oil at $100^{\circ} \mathrm{C}$, and presented $99 \%$ remaining mass after decomposition experiment up to $180^{\circ} \mathrm{C}$. This research thus contributes in suggesting compositions of rubber composites in seal applications, in which emerging and promising modified natural rubber material is included.

\section{Acknowledgment}

The authors gratefully acknowledge the Ministry of Industry, Indonesia for financial support and Mrs. Arum Yuniari who forwarded the idea of developing this research. All authors also thank Malaysian Rubber Board for providing the ENR. The main contributors to this manuscript were Hesty Eka Mayasari, Muhammad Sholeh, and Norma Arisanti Kinasih. Funding Body: Ministry of Industry, Indonesia. 


\section{References}

[1] V.C. Chandrasekaran, Rubber Seals for Fluid and Hydraulic Systems, 2010, Oxford: William Andrew Publishing.

[2] H.S. Ahmad, H. Ismail, A.A. Rashid, Tensile properties and morphology of epoxidized natural rubber/recycled acrylonitrile-butadiene rubber (ENR 50/NBRr) blends, Procedia Chemistry, 19, 2016, pp. 359-365.

[3] M.S. Perera, U.S. Ishiaku, Z.M. Ishak, Characterisation of PVC/NBR and PVC/ENR50 binary blends and PVC/ENR50/NBR ternary blends by DMA and solid state NMR, European Polymer Journal, 37(1), 2001, pp. 167-178.

[4] K.M. George, J.K. Varkey, K.T. Thomas, N.M. Mathew, Epoxidized natural rubber as a reinforcement modifier for silica-filled nitrile rubber, Journal of Applied Polymer Science, 85(2), 2002, pp. 292-306.

[5] A.Z. Romli, S.N. Mamauod, Physical and mechanical properties of ENR compatibilized NR/NBR blends reinforced nanoclay and nanosilica, Macromolecular Symposia, 371(1), 2017, pp. $27-$ 34.

[6] K. Pal, S.K. Pal, C.K. Das, J.K. Kim, Effect of fillers on morphological and wear characteristics of NR/HSR blends with E-glass fiber, Materials \& Design, 35, 2012, pp. 863-872.

[7] S. Yang, Z. Liu, Y. Jiao, Y. Liu, W. Luo, Study on the compatibility and crystalline morphology of NBR/PEO binary blends, Journal of Material Science, 48, 2013, pp. 6811-6817.

[8] S. Chakraborty, S. Bandyopadhyay, R. Ameta, R. Mukhopadhyay, A.S. Deuri, Application of FTIR in characterization of acrylonitrile-butadiene rubber (nitrile rubber), Polymer Testing, 26, 2007, pp. 38-41.

[9] M. Bijarimi, S. Ahmad, R. Rasid, Mechanical, thermal and morphological properties of poly(lactic acid)/epoxidized natural rubber blends, Journal of Elastomers and Plastics, 2012, pp. 1-7.

[10] F. Harun, C.H. Chan, Electronic Applications of Polymer Electrolytes of Epoxidized Natural Rubber and Its Composites. In: Flexible and Stretchable Electronic Composites, Springer, Cham, 2016, pp. 37-59.

[11] S. Chuayjuljit, P. Mungmeechai, A. Boonmahitthisud, Mechanical properties, thermal behaviors and oil resistance of epoxidized natural rubber/multiwalled carbon nanotube nanocomposites prepared via in situ epoxidation, Journal of Elastomer \& Plastics, 2016, pp. 1-21.

[12] Klinger, Product Catalogue: Industrial Sealing Division, n.d., Klinger. 